\title{
Endophthalmitis caused by Pantoea agglomerans: clinical features, antibiotic sensitivities, and outcomes
}

This article was published in the following Dove Press journal:

Clinical Ophthalmology

7 July 2015

Number of times this article has been viewed

\section{Vincent $D$ Venincasa \\ Ajay E Kuriyan \\ Harry W Flynn Jr \\ Jayanth Sridhar \\ Darlene Miller}

Department of Ophthalmology, Bascom Palmer Eye Institute, Miller School of Medicine, University of Miami, Miami, FL, USA
Correspondence: Ajay E Kuriyan Department of Ophthalmology, Bascom Palmer Eye Institute, Miller School of Medicine, University of Miami, 900 NW 17th Street, Miami, FL 33|36, USA

$\mathrm{Tel}+\mathrm{I} 3053266000$

Fax +I 3053266417

Email ajay.kuriyan@gmail.com
Purpose: To report the clinical findings, antibiotic sensitivities, and visual outcomes associated with endophthalmitis caused by Pantoea agglomerans.

Methods: A consecutive case series of patients with vitreous culture-positive endophthalmitis caused by P. agglomerans from January 1, 1990 to December 31, 2012 at a large university referral center. Findings from the current study were compared to prior published studies.

Results: Of the three study patients that were identified, clinical settings included trauma $(n=2)$ and post-cataract surgery $(n=1)$. Presenting visual acuity was hand motion or worse in all three cases. All isolates were sensitive to ceftazidime, gentamicin, imipenem, and fluoroquinolones. All isolates were resistant to ampicillin. Initial treatment strategies were vitreous tap and intravitreal antibiotic injection $(\mathrm{n}=1)$ and pars plana vitrectomy with intravitreal antibiotic injection $(\mathrm{n}=2)$. At last follow-up, one patient had no light perception vision, while the other two had best-corrected visual acuity of 20/200 and 20/400.

Conclusion: All Pantoea isolates were sensitive to ceftazidime, gentamicin, imipenem, and fluoroquinolones. All patients in the current study received at least one intravitreal antibiotic to which $P$. agglomerans was shown to be sensitive in vitro. In spite of this, the visual outcomes were generally poor.

Keywords: ocular infection, trauma, antibiotic resistance

\section{Introduction}

Pantoea agglomerans (previously classified as Bacillus agglomerans and Enterobacter agglomerans) is a Gram-negative aerobic bacillus that is ubiquitous in nature. $P$. agglomerans is most commonly found on vegetation, and rarely causes disease in humans. ${ }^{1}$ To date, there have been eleven published cases of endophthalmitis caused by $P$. agglomerans, but no cases have been reported from the United States since $1989 .^{2-7}$ There were no cases of endophthalmitis caused by $P$. agglomerans in the Endophthalmitis Vitrectomy Study. ${ }^{8}$

The purpose of this study is to describe the clinical features, antibiotic susceptibilities, and visual acuity outcomes of three patients with endophthalmitis caused by $P$. agglomerans in the United States. Very limited data exist on P. agglomerans across all disciplines of medicine; however, the most common reports involve septicemia and septic arthritis following penetrating trauma with plant matter or nosocomial infections. ${ }^{1,9,10}$ Over the last decade, there have been several septicemia outbreaks in neonatal centers secondary to contaminated parenteral nutrition, ${ }^{11}$ intravenous fluids, ${ }^{12}$ and contaminated anticoagulant citrate-dextrose $46 \%$ solution. ${ }^{13}$ Based on a PubMed search, this is the largest series of $P$. agglomerans endophthalmitis to be reported from 
the United States. Using published literature for comparison, this is the first study to evaluate antibiotic sensitivities of isolates of $P$. agglomerans in patients with endophthalmitis from different regions.

\section{Methods}

Institutional review board approval was obtained from the University of Miami Miller School of Medicine Sciences Subcommittee for the Protection of Human Subjects. The Ocular Microbiology Department database was searched to identify all patients with positive vitreous cultures for P. agglomerans (E. agglomerans) between January 1, 1990 and December 31, 2012 at the Bascom Palmer Eye Institute (Miami, FL, USA). Records from the microbiology department were reviewed to identify microbial isolates and antibiotic sensitivities.

Vitreous cultures were obtained during vitrectomy or at the time of vitreous tap. Fluid from a vitreous tap was placed directly onto culture media including $5 \%$ sheep blood and chocolate agars. For vitrectomy specimens, $30-50 \mathrm{~mL}$ of vitreous washings were filtered using a $0.45 \mu \mathrm{m}$ filter. The resultant filter paper was divided into sections and plated onto different culture media, which typically included chocolate and blood agars. Blood and chocolate agars underwent incubation at $35^{\circ} \mathrm{C}$ for up to 2 weeks. Additional culture media, including thioglycollate broth, were performed at the discretion of the ophthalmologist performing the culture. All cultures were read and classified by the Ocular Microbiology Department staff using the VITEK automated microbial system (Biomerieux Vitek, Hazelwood, MO, USA). The medical records of each patient listed in our database with a positive $P$. agglomerans culture were reviewed to ensure they had a clinical course consistent with endophthalmitis. Patient demographics, clinical features, treatment strategies, and clinical outcomes were assessed. The clinical features, treatment strategies, and clinical outcomes from our institution were compared to those from previously published cases. Additionally, a comparison was made between the antibiotic resistance patterns between isolates from the United States and Asia. ${ }^{2-7}$

\section{Results}

Over the 23-year study period, three eyes of three patients were successfully identified with endophthalmitis secondary to $P$. agglomerans. The initial presentation, management, and outcomes are summarized in Table 1. The patients were 10-, 14-, and 72-years old with follow-up times of 52 months, 2 months, and 5 months, respectively. $P$. agglomerans has

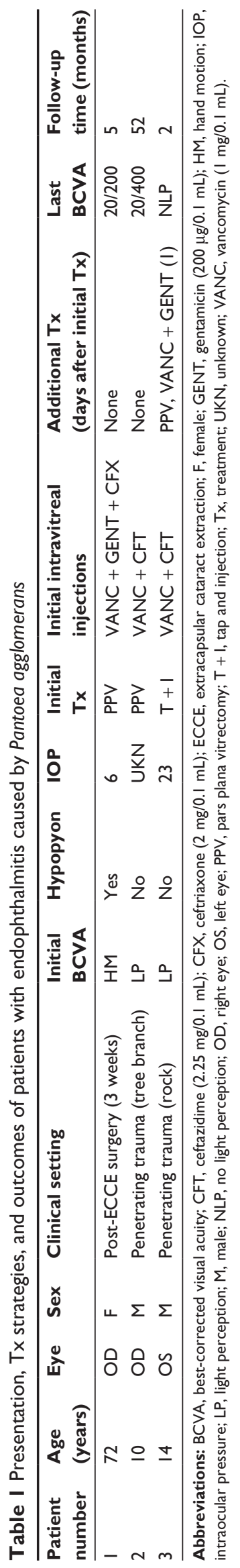




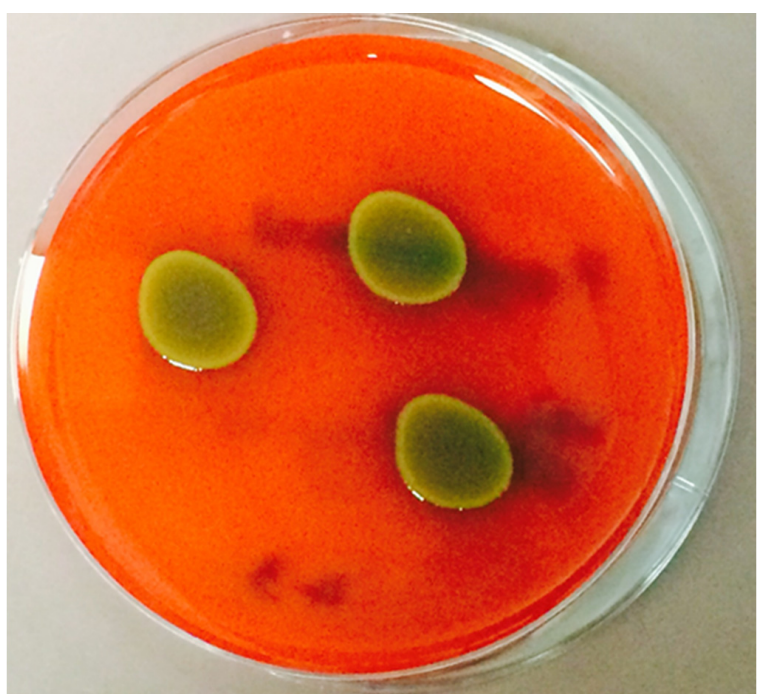

Figure I Growth of Pantoea agglomerans on a blood agar culture plate. Notes: The yellow color of the growing colonies is characteristic of $P$. agglomerans. These colonies were grown from the vitreous sample from patient number 2 .

distinct yellow-colored colonies when grown in a blood agar culture plate (Figure 1). All patients in this study presented with best-corrected visual acuity (BCVA) of hand motion or worse. Two of the patients developed endophthalmitis secondary to penetrating trauma with corneoscleral lacerations. Two patients were initially treated with pars plana vitrectomy with injection of intravitreal antibiotics. The third patient was treated with a vitreous tap and injection of antibiotics and underwent a planned pars plana vitrectomy (with injection of vancomycin and gentamicin) 1 day later for removal of an intraocular foreign body. At last follow-up, one patient had no light perception vision, while the other two had BCVA of 20/200 and 20/400.
All isolates were resistant to ampicillin, and two isolates were resistant to cefazolin. No isolates were resistant to the other antibiotics tested, including ceftazidime, gentamicin, imipenem, and fluoroquinolones, as shown in Table 2.

\section{Discussion}

P. agglomerans was originally identified as B. agglomerans in $1888 .{ }^{14}$ However, in 1972, it was reclassified as E. agglomerans based on a biochemical reaction profile that was similar to Enterobacter genus and differentiated it from Bacillus genus. ${ }^{14}$ In 1989, it was again reclassified as $P$. agglomerans, since it does not utilize the amino acids lysine, arginine, and ornithine, which differentiates it from the Enterobacter genus. ${ }^{15}$

Very few cases of endophthalmitis caused by P. agglomerans have been published due to its rarity as a pathogen in humans. A comparison between the three cases in the current series and all eleven previously reported cases of endophthalmitis caused by P. agglomerans (based on a PubMed search) is summarized in Table 3. Of note, there was a large proportion of cases associated with trauma $(6 / 11,55 \%)$, similar to the current study. Also, in the previously reported cases, four $(36 \%)$ of eleven patients had a BCVA at last follow-up of $20 / 50$ or better, compared to none of the patients in the current study. Since many of the cases involve penetrating trauma, poor visual outcomes can be attributed to both the endophthalmitis and the associated trauma.

A PubMed search was performed to identify all previously published cases of endophthalmitis caused by $P$. agglomerans with antibiotic resistance data. When combining the cases from the United States and Asia, isolates of $P$. agglomerans were resistant to ampicillin $(5 / 10,56 \%)$,

Table 2 Antibiotic resistance of Pantoea agglomerans isolates

\begin{tabular}{|c|c|c|c|c|}
\hline \multirow[t]{2}{*}{ Antibiotic } & \multirow{2}{*}{$\begin{array}{l}\text { Resistant isolates } \\
\text { (number tested) }\end{array}$} & \multicolumn{3}{|c|}{ Minimal inhibitory concentration ug/mL } \\
\hline & & Patient I & Patient 2 & Patient 3 \\
\hline \multicolumn{5}{|l|}{ Beta-lactams } \\
\hline Ampicillin & $3(3)$ & 32 & 32 & 32 \\
\hline Aztreonam & $0(2)$ & - & 8 & 8 \\
\hline Cefotaxime & $0(2)$ & 4 & 32 & - \\
\hline Ceftazidime & $0(3)$ & 8 & 8 & 8 \\
\hline Ceftriaxone & $0(2)$ & - & 8 & 8 \\
\hline Imipenem & $0(2)$ & - & 4 & 4 \\
\hline \multicolumn{5}{|l|}{ Fluoroquinolones } \\
\hline Ciprofloxacin & $0(3)$ & 0.5 & 0.5 & 0.5 \\
\hline Levofloxacin & $0(2)$ & - & 0.5 & 1 \\
\hline \multicolumn{5}{|l|}{ Aminoglycosides } \\
\hline Amikacin & $0(2)$ & - & 2 & 2 \\
\hline Gentamicin & $0(3)$ & 0.5 & I & 0.5 \\
\hline Tobramycin & $0(3)$ & 0.5 & 0.5 & 0.5 \\
\hline
\end{tabular}


Table 3 Comparison of patient presentation, initial treatment, and visual acuity outcomes between this study and all other reported cases in the literature

\begin{tabular}{|c|c|c|}
\hline & $\begin{array}{l}\text { Current study } \\
\text { January } 1990 \text { - December } 2012 \\
\text { P. agglomerans }(n=3)\end{array}$ & $\begin{array}{l}\text { Previously reported cases }{ }^{2-7} \\
\text { January } 1976 \text { - January } 2014 \\
\text { P. agglomerans }(n=I I)\end{array}$ \\
\hline & Number of patients (\%) & Number of patients (\%) \\
\hline \multicolumn{3}{|l|}{ Clinical setting } \\
\hline Post-cataract surgery & I (33) & I (9) \\
\hline Traumatic & $2(66)$ & $6(55)$ \\
\hline Endogenous & $0(0)$ & $4(36)$ \\
\hline \multicolumn{3}{|l|}{ Initial treatment } \\
\hline Vitreous tap + antibiotics & I (33) & $3(27)$ \\
\hline PPV + antibiotics & $2(66)$ & $8(73)$ \\
\hline Intravitreal corticosteroids & I (33) & $5(45)$ \\
\hline \multicolumn{3}{|l|}{ Visual acuity outcomes } \\
\hline$\geq 20 / 50$ & $0(0)$ & $4(36)$ \\
\hline$\geq 20 / 400$ & I (33) & $3(27)$ \\
\hline$<20 / 400$ & $2(66)$ & $4(36)$ \\
\hline
\end{tabular}

Abbreviations: P. agglomerans, Pantoea agglomerans; PPV, pars plana vitrectomy.

cefazolin $(3 / 8,38 \%)$, and ceftazidime $(2 / 9,22 \%)$ (Table 4$)$. A comparison of the antibiotic resistance of $P$. agglomerans isolates from endophthalmitis cases in the United States and Asia is summarized in Table 3. Of note, the isolates from Asia had high rates of resistance to ceftazidime (2/6,33\%), compared to no resistance among isolates from the United States $(0 / 3,0 \%)$. None of the isolates from either region were resistant to gentamicin, fluoroquinolones, or imipenem. Although this comparison of antibiotic resistance between the different studies provides important information about regional differences in resistance, the comparison is limited by the use of different methods of antibiotic susceptibility testing and possibly different breakpoints for resistance in different laboratories and across different time periods.

\section{Conclusion}

P. agglomerans is a rare but potential cause of endophthalmitis, especially in the setting of penetrating trauma with plant matter. Despite prompt treatment with at least one antibiotic that the isolates were susceptible to (ceftazidime, ceftriaxone, and/or gentamicin), patients in the current study generally had poor visual acuity outcomes. This study demonstrates regional differences in antibiotic resistance to ceftazidime, one of the most commonly used intravitreal antibiotics.

Table 4 Comparison of antibiotic resistance of Pantoea agglomerans isolates causing endophthalmitis from the United States and Asia

\begin{tabular}{|c|c|c|c|c|}
\hline \multirow[t]{2}{*}{ Antibiotic } & \multirow{2}{*}{$\begin{array}{l}\text { All US studies }^{6}(n=4)^{a} \\
\text { Resistant isolates } \\
\text { (number tested) }\end{array}$} & \multirow{2}{*}{$\begin{array}{l}\text { Asian studies }^{2,3}(\mathrm{n}=6) \\
\text { Resistant isolates } \\
\text { (number tested) }\end{array}$} & \multicolumn{2}{|l|}{ Total $^{2,3,6}(n=10)$} \\
\hline & & & $\begin{array}{l}\text { Resistant isolates } \\
\text { (number tested) }\end{array}$ & $\begin{array}{l}\text { Resistant } \\
\text { (\%) }\end{array}$ \\
\hline \multicolumn{5}{|l|}{ Beta-lactams } \\
\hline Ampicillin & $3(4)$ & $2(6)$ & $5(10)$ & 50 \\
\hline Aztreonam & $0(2)$ & $0(I)$ & $0(3)$ & 0 \\
\hline Cefotaxime & $0(2)$ & $0(1)$ & $0(3)$ & 0 \\
\hline Ceftazidime & $0(3)$ & $2(6)$ & $2(9)$ & 22 \\
\hline Ceftriaxone & $0(2)$ & I (5) & I (7) & 14 \\
\hline Imipenem & $0(2)$ & $0(6)$ & $0(8)$ & 0 \\
\hline \multicolumn{5}{|l|}{ Fluoroquinolones } \\
\hline Ciprofloxacin & $0(3)$ & $0(I)$ & $0(4)$ & 0 \\
\hline Levofloxacin & $0(2)$ & $0(5)$ & $0(7)$ & 0 \\
\hline \multicolumn{5}{|l|}{ Aminoglycosides } \\
\hline Amikacin & $0(2)$ & $0(6)$ & $0(8)$ & 0 \\
\hline Gentamicin & $0(4)$ & $0(6)$ & $0(10)$ & 0 \\
\hline Tobramycin & $0(3)$ & $0(I)$ & $0(4)$ & 0 \\
\hline
\end{tabular}

Notes: Three previously published cases did not publish sensitivities and could not provide them upon request (Zeiter et al, ${ }^{7}$ Kletke et al, ${ }^{5}$ and Seok et al ${ }^{4}$ ). ${ }^{2}$ Includes the current US study. 


\section{Disclosure}

The authors report no conflicts of interest in this work.

\section{References}

1. Cruz AT, Cazacu AC, Allen CH. Pantoea agglomerans, a plant pathogen causing human disease. J Clin Microbiol. 2007;45(6):1989-1992.

2. Sudhalkar A, Majji AB, Chhablani J, Manderwad G. Pantoea agglomerans endophthalmitis: clinical features and outcomes. Retina. 2014; 34(8):1702-1706.

3. Lee NE, Chung IY, Park JM. A case of Pantoea endophthalmitis. Korean J Ophthalmol. 2010;24(5):318-321.

4. Seok S, Jang YJ, Lee SW, Kim HC, Ha GY. A case of bilateral endogenous Pantoea agglomerans endophthalmitis with interstitial lung disease. Korean J Ophthalmol. 2010;24(4):249-251.

5. Kletke SN, Brissette AR, Gale J. Endogenous bacterial endophthalmitis caused by Pantoea species: a case report. Can J Ophthalmol. 2014; 49(1):e1-e2.

6. Mason GI, Bottone EJ, Podos SM. Traumatic endophthalmitis caused by an Erwinia species. Am J Ophthalmol. 1976;82(5):709-713.

7. Zeiter JH, Koch DD, ParkE DW 2nd, Font RL. Endogenous endophthalmitis with lenticular abscess caused by Enterobacter agglomerans (Erwinia species). Ophthalmic Surg. 1989;20(1):9-12.

8. Endophthalmitis Vitrectomy Study Group. Results of the Endophthalmitis Vitrectomy Study. A randomized trial of immediate vitrectomy and of intravenous antibiotics for the treatment of postoperative bacterial endophthalmitis. Endophthalmitis Vitrectomy Study Group. Arch Ophthalmol. 1995;113(12):1479-1496.
9. De Champs C, Le Seaux S, Dubost JJ, Boisgard S, Sauvezie B, Sirot J. Isolation of Pantoea agglomerans in two cases of septic monoarthritis after plant thorn and wood sliver injuries. $J$ Clin Microbiol. 2000;38(1):460-461.

10. Ulloa-Gutierrez R, Moya T, Avila-Aguero ML. Pantoea agglomerans and thorn-associated suppurative arthritis. Pediatr Infect Dis J. 2004;23(7):690.

11. Habsah H, Zeehaida M, Van Rostenberghe H, et al. An outbreak of Pantoea spp. in a neonatal intensive care unit secondary to contaminated parenteral nutrition. J Hosp Infect. 2005;61(3):213-218.

12. Bicudo EL, Macedo VO, Carrara MA, Castro FF, Rage RI. Nosocomial outbreak of Pantoea agglomerans in a pediatric urgent care center. Braz J Infect Dis. 2007;11(2):281-284.

13. Boszczowski I, Nóbrega de Almeida Júnior J, Peixoto de Miranda EJ, et al. Nosocomial outbreak of Pantoea agglomerans bacteraemia associated with contaminated anticoagulant citrate dextrose solution: new name, old bug? J Hosp Infect. 2012;80(3):255-258.

14. WH Ewing and Fife MA. Enterobacter agglomerans (Beijerinck) comb. nov. (the Herbicola-Lathyri Bacteria). International Journal of Systemic Bacteriology. 1972;22(1):4-11.

15. Gavini F, Mergaert J, Beji A, et al. Transfer of Enterobacter agglomerans (Beijerinck 1888) Ewing and Fife 1972 to Pantoea gen. nov. as Pantoea agglomerans comb. nov. and Description of Pantoea dispersa sp. nov. Int J Syst Bacteriol. 1989;39(3):337-345.
Clinical Ophthalmology

\section{Publish your work in this journal}

Clinical Ophthalmology is an international, peer-reviewed journa covering all subspecialties within ophthalmology. Key topics include: Optometry; Visual science; Pharmacology and drug therapy in eye diseases; Basic Sciences; Primary and Secondary eye care; Patien Safety and Quality of Care Improvements. This journal is indexed on

Submit your manuscript here: http://www.dovepress.com/clinical-ophthalmology-journal

\section{Dovepress}

PubMed Central and CAS, and is the official journal of The Society of Clinical Ophthalmology (SCO). The manuscript management system is completely online and includes a very quick and fair peer-review system, which is all easy to use. Visit http://www.dovepress.com/ testimonials.php to read real quotes from published authors. 